\section{John Cowdery Kendrew (1917-97)}

\section{Pioneer in structural biology and collaborative biological research in Europe}

“... and in a jungle in Ceylon, J. D. Bernal talked with John Kendrew about the way it should be possible to use X-rays to solve the structure of proteins and so to understand their function in every living organism." Thus wrote Dorothy Hodgkin about how wartime operational research, concerned with elephants and bombs, inspired Kendrew's ensuing research career.

Sir John Kendrew died on 23 August, aged 80. He was educated at schools in Oxford and Bristol, and took his undergraduate degree (a first in chemistry) in 1939, at Trinity College, Cambridge. Like so many other scientists, during the Second World War he worked on radar, before being posted to southeast Asia as scientific adviser to the Allied Air Command.

At the outbreak of peace he sought out Max Perutz, an erstwhile student of Bernal's. Impressed by Kendrew's uniform as a wing commander, Perutz took him on as his second in command to work in the fledgling Medical Research Council unit for molecular biology at the Cavendish Laboratory, Cambridge, under Sir Lawrence Bragg (Kendrew may also have benefited from his entitlement to the residue of a senior scholarship from Trinity, which meant he didn't cost too much). This extraordinarily fruitful collaboration led to the joint award of the Nobel prize for chemistry just over a decade later. Moreover, they recruited Francis Crick, Hugh Huxley, Jim Watson and Sydney Brenner to the unit, all of whom became prime movers in modern biology, and a dazzling array of postdoctoral students passed through the lab.

Perutz set out to solve the structure of haemoglobin, the oxygen carrier in blood. Kendrew chose myoglobin, haemoglobin's small brother. The first attempt was with horse myoglobin but this would not crystallize properly. Try another species? Kendrew realized that myoglobin, an oxygen storage protein found in muscle, should be abundant in aquatic mammals. For reasons connected with the war, the nearby 'low-temperature laboratory' had cold rooms stuffed with whale meat, which duly yielded crystals of the quality necessary for X-ray diffraction.

How does one work out the structure of a molecule containing thousands of atoms? In principle it's easy: you collect the $\mathrm{X}$-ray diffraction data from the crystal in all

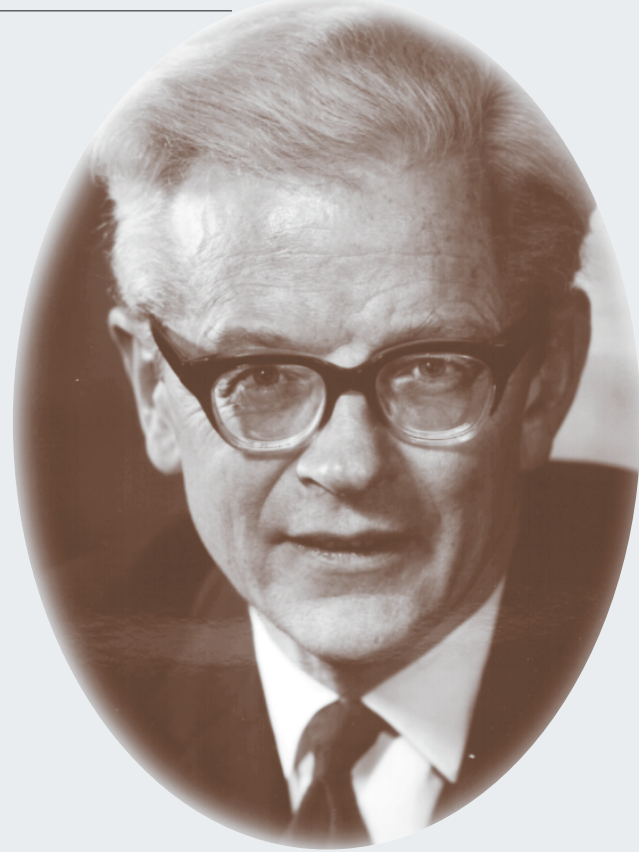

orientations and compute the Fourier transform to give the electron density. Unfortunately, the diffracted intensities yield only the amplitudes; the phases are lost, but it was thought that they might be recovered by adding a heavy metal at a specific site in each molecule. To everyone's surprise this method worked and was used by Perutz to calculate a projection map of haemoglobin in 1953. Kendrew applied this method to myoglobin using threedimensional data and many different heavy atoms, and in 1957 produced the first low-resolution map of a protein. It showed myoglobin to be almost entirely $\alpha$ helical, the helices being coiled round each other and round the haem group.

Four years later Kendrew had the coordinates of the 1,250 non-hydrogen atoms in myoglobin, an epoch-making achievement. The enormous impact that these discoveries were to have on biochemistry was only slowly appreciated by classical biochemists, which in 1958 motivated Kendrew to found the Journal of Molecular Biology.

Kendrew ran his lab as chief of staff. He himself developed numerical techniques for finding the relative positions of the heavy atoms. Automatic methods for measuring the intensities of some 100,000 Bragg reflections were devised. Numerous computing ladies were entrusted with the collection and collation of all the data. Bigger and better $\mathrm{X}$-ray sources were built. Early experiences had convinced Hugh Huxley that computing Fourier summations by hand was not a task befitting the human condition. As a result he had introduced Kendrew to a friend, John Bennett from the Cambridge computer lab (EDSAC). In 1952, Bennett and Kendrew wrote a three-dimensional Fourier program, probably the first.

In 1962 Perutz and Kendrew were awarded the Nobel prize. That same year they moved into the splendid new MRC Laboratory of Molecular Biology on Hills Road, Cambridge, with Perutz as director, and Kendrew as deputy director and head of the division of structural studies.

However, he was restless, in search of new organizational peaks to conquer. In parallel to his Cambridge appointment he was deputy scientific adviser to the Ministry of Defence and later chairman of the Defence Scientific Advisory Committee, which earned him his knighthood. At the same time plans for a European Molecular Biology Laboratory, to be modelled on the particle-physics research facility CERN, were taking shape. Kendrew was appointed project leader and carried out all the intricate negotiations leading to the successful founding of this laboratory in Heidelberg in 1974 (he would have preferred Nice, but France had just got the new CERN ring so Germany must have EMBL).

In Heidelberg, he made the theme technology for molecular biology. He set up the EMBL outstations at DESY (Hamburg) and ILL (Grenoble) for synchrotron light as an X-ray source and for neutron scattering; the DESY outstation was the first in the world to use synchrotron radiation as a source for X-ray diffraction. In the Heidelberg laboratory he promoted many technologies, particularly cryo-electron and optical microscopy. Furthermore, he hired bright young project leaders and gave them freedom to develop. By the time he retired as director-general in 1982 he had built up a world-class laboratory.

Between 1982 and 1988 John Kendrew was vice-president and then president of the International Council of Scientific Unions, and he was a governor of the Weizmann Institute, Israel, where he had many friends. On leaving EMBL he was appointed president of St John's College, Oxford, and was very happy to return to the city of his childhood and once more to work with students. In his Cambridge days he was a Fellow of Peterhouse College, and shortly before his death was awarded an honorary doctorate by the university, which occasioned him great pride.

\section{K.C. Holmes}

K. C. Holmes is in the Max-Planck-Institut für Medizinische Forschung, Abteilung Biophysik, Jahnstrasse 29, D-69120 Heidelberg, Germany. e-mail:holmes@otto.mpimf-heidelberg.mpg.de 